\title{
Klasifikasi Support Vector Machine (SVM) Untuk Menentukan TingkatKemanisan Mangga Berdasarkan Fitur Warna
}

\author{
MUHAMMAD ICHWAN, IRMA AMELIA DEWI, ZENI MUHAROM S \\ Institut Teknologi Nasional \\ Email: michwan86@gmail.com
}

\begin{abstract}
ABSTRAK
Dalam proses penentuan mutu atau tingkat kemanisan buah mangga cengkir di pasaran pada umumnya dilakukan dengan dengan dua cara yaitu menggunakan pakar-pakar untuk pemilihan / sortasi kemanisan mangga atau menggunakan metode destruktif dengan cara pengambilan sampel, uji coba kemanisan mangga tersebut seperti menggunakan Refractometer. Permasalahan yang terjadi pada kedua proses tersebut yaitu memiliki cost yang relative besar dan tidak menghasilkan mutu yang seragam karena sortasi tingkat kemanisan mangga oleh pakar bersifat subjektif dan kemungkinan terjadinya kesalahan pengamatan sangat. Support Vector Machine (SVM) diimplementasikan pada penelitian ini dan $K$-Nearest Neighbour (K-NN) sebagai metoda pembanding untuk klasifikasi citra warna buah mangga cengkir. Dalam penelitan ini perbandingan antara kedua metode tersebut dibandingkan dengan hasil output dari alat pengukur tingkat kemanisan yaitu refractometer sebanyak 24 objek pengujian dengan akurasi sebesar $83,3 \%$. Sedangkan hasil yang diperoleh dari metode $K-N N$ dengan $k=7$ adalah data valid 21 buah dari 24 buah, dan data tidak valid 3 buah dari 24 buah.
\end{abstract}

Kata kunci : Tingkat Kemanisan, SVM, K-NN, HSV.

\section{ABSTRACT}

In the process of determining the quality or sweetness level of cengkir mango on the market, it is generally done with two programs, namely using experts to select I sort the sweetness of mango based on the expert perspective, or using destructive methods by sampling, test the sweetness of the mango such as using a Refractometer. The problems that occur in both processes are that they have relatively large costs and do not produce uniform quality because the sorting level of sweetness of mangoes by experts is subjective and the possibility of observing errors is very large. Therefore in this study the development of the system using Support Vector Machine (SVM) and K-Nearest Neighbor (K-NN) was carried out as a comparison method in classifying color images of clove mango. In this research, the comparison between the two methods is compared with the output of sweetness level measuring devices, namely 24 refractometers with 83.3\% accuracy. While the results obtained from the $K-N N$ method with $k=7$ are valid data 21 pieces of 24 pieces, and invalid data 3 pieces of 24 pieces.

Keywords: Sweetness level, SVM, K-NN, HSV. 


\section{PENDAHULUAN}

Salah satu tahapan dalam pasca panen mangga cengkir yang perlu mendapat perhatian adalah sortasi dan pemutuan (menentukan mutu). Pada umumnya kegiatan penentuan mutu di pasaran dilakukan secara manual dan dilakukan oleh lebih dari satu orang sehingga produk yang dihasilkan memiliki mutu yang kurang seragam karena penentuan mutu bersifat subjektif.

Mengacu pada peningkatan metode sortasi dan penentuan mutu mangga cengkir maka diperlukan suatu metode untuk memprediksi tingkat kemanisan dari buah mangga tersebut sehingga diperoleh pemutuan mangga cengkir yang seragam.

Pada penelitian ini dilakukan klasifikasi penentuan tingkat kemanisan manga cengkir dengan metode Support Vector Machine (SVM) dan K-Nearest Neighbour (K-NN), berdasarkan citra yang diambil oleh kamera. Citra yang diambil diolah pada proses image processing. Proses image processing tersebut umumnya bertujuan untuk memperbaiki kualitas suatu gambar, namun dapat pula digunakan untuk sistem penentuan suatu produk dengan cara mendapatkan nilai citra yang diperlukan dari suatu objek tersebut, kemudian nilai citra yang didapat akan diklasifikasikan menggunakan metode klasifikasi seperti metode SVM (Support Vector Machine) dan K-NN (K-Nearest Neigbour).

\section{METODE PENELITIAN}

Dalam proses penentuan mutu atau tingkat kemanisan buah mangga cengkir di pasaran pada umumnya dilakukan dengan dengan dua acara yaitu menggunakan pakar-pakar untuk pemilihan / sortasi kemanisan mangga berdasarkan perspektif pakar tersebut, dan menggunakan metode destruktif dengan cara pengambilan sampel, buah mangga cengkir akan dibelah dan diambil sampelnya untuk uji coba kemanisan mangga tersebut (Sri Agustina, 2015). Permasalahan yang terjadi pada kedua proses tersebut yaitu memiliki cost yang relative besar dan tidak menghasilkan mutu yang seragam karena sortasi tingkat kemanisan mangga oleh pakar bersifat subjektif dan kemungkinan terjadinya kesalahan pengamatan sangat besar (Ibnu Wanhar, 2016).

\subsection{BRIX}

Brix merupakan unit pengukur tingkat kemanisan gula di dalam cairan (liquid). Satuan brix yang digunakan ialah derajat brix. Skala brix ditemukan oleh ilmuwan Jerman. Adolf Ferdinand W Brix (1798 - 1870) di tahun 1870. 1\% Brix setara dengan 1gram gula sukrosa di dalam 100 gram air. Berikut nilai unit Brix di buah-buahan. 


\begin{tabular}{|c|c|c|c|c|}
\hline No & Buah & $\begin{array}{c}\text { yel 1. Derajat } \\
\text { Tidak Manis }\end{array}$ & Sedang & Manis \\
\hline 1 & Apel & $<6$ & $6-14$ & $14>$ \\
\hline 2 & Alpukat & $<4$ & $6-8$ & $8>$ \\
\hline 3 & Anggur & $<8$ & $8-12$ & $12>$ \\
\hline 4 & Blewah & $<8$ & $8-12$ & $12>$ \\
\hline 5 & Mangga & $<8$ & $8-12$ & $12>$ \\
\hline 6 & Nanas & $<12$ & $12-14$ & $14>$ \\
\hline 7 & Pisang & $<8$ & $8-12$ & $12>$ \\
\hline 8 & Pepaya & $<6$ & $6-10$ & $10>$ \\
\hline 9 & Persik & $<6$ & $6-14$ & $14>$ \\
\hline 10 & Pir & $<6$ & $6-12$ & $12>$ \\
\hline
\end{tabular}

Sumber: Bionutrient

\subsection{Refractometer}

Refractometer merupakan alat pengukuran konsentrasi zat yang terlarut yang ditemukan oleh Dr. Ernest Abbe, seorang ilmuan dari German Sekitar tahun 2010 an. Brix(\%) digunakan untuk menyatakan Konsentrasi bahan terlarut yang merupakan prosentasi bahan terlarut dalam larutan air.

\subsection{Citra}

Citra merupakan gambar dua dimensi dari gambar analog yang kontinu menjadi gambar diskrit melalui proses sampling. Gambar analog dibagi menjadi $\mathrm{N}$ baris dan $\mathrm{M}$ kolom sehingga menjadi gambar diskrit. Pixel merupakan Persilangan baris dan kolom.

\subsection{Model Warna HSV}

HSV adalah model warna yang lebih baik untuk digunakan untuk berbagai keperluan pengolahan citra dan computervision. Hue $(\mathrm{H})$ adalah ukuran dari jenis warna seperti warna merah, kuning, hijau, dan seterusnya. Representasinya dalam bentuk derajat dengan nilai 0 - 360. Saturasi (S) adalah keberwarnaan suatu warna. Semakin berwarna sebuah warna berarti semakin besar nilai saturasinya. Namun apabila suatu warna pucat, itu berarti saturasinya rendah. Value (V) adalah nilai kecerahan sebuah warna. Warna cerah memiliki nilai value tinggi dan sebaiknya untuk warna yang gelap.

\subsection{Support Vector Machine (SVM)}

Teori dasar dari Support Vector Machine (SVM) telah berkembang pada tahun 1992 dan sudah berkambang dengan pesat, dimana SVM adalah proses pembelajaran dengan menggunakan ruang hipotesis yang terdiri dari fungsi-fungsi linier dalam sebuah ruang fitur (feature space) berdimensi tinggi. Proses latih algoritma pembelajaran adalah proses optimasi dimana learning bias diimplementasikan. SVM memiliki unjuk kerja yang baik untuk diimplemtasikan pada bioinformatics, pengenalan, tulisan tangan, klasifikasi dan lain sebagainya (Krisatus Sembiring, 2008).

\subsection{SVM ONE-AGAINST-ONE}

Pengklasifikasian menggunakan SVM pada awalnya terbatas untuk dua kelas. Dengan kata lain, SVM adalah pengklasifikasi biner (binary classifier). Namun, sejumlah penelitian lebih lanjut memungkinkan SVM menjadi multi kelas (multi class) yang mampu mengklasifikasi data ke dalam kelas yang lebih banyak. One-Against-One, pada metode ini diharuskan 
membangun sejumlah model SVM biner yang membandingkan satu kelas dengan kelas lainnya seperti dalam kompetisi penuh pertandingan bola. Untuk mengklasifikasikan data ke dalam $k$ kelas, diharuskan membangun sejumlah $\frac{k(k-1)}{2}$ model SVM biner. Untuk masalah klasifikasi dengan 4 kelas, maka harus membangun $\frac{4(4-1)}{2}=6$ buah SVM biner. SVM biner pertama dilatih menggunakan data latih dari kelas pertama dan kelas kedua untuk mengklasifikasikan data ke dalam kelas $\mathrm{C} 1$ atau C2. SVM biner kedua dilatih menggunakan data latih dari kelas C2 atau C3, dan seterusnya. Artinya, setiap kelas harus dibandingkan dengan tiga kelas lainnya. Untuk mendapatkan kelas keputusan, dapat digunakan cara voting. Sehingga, kelas yang paling sering menang adalah kelas keputusan..

\subsection{Bahan dan Peralatan}

Alat dan bahan yang digunakan pada penelitian ini adalah Laptop \& Kamera, Windows 10, Wamp, Netbeans IDE, Java Development Kit, Python, Library OpenCV, seta MySQL.

\section{HASIL DAN PEMBAHASAN}

Cara kerja sistem yang dibuat melingkupi load image gambar buah mangga, kemudian sistem akan memotong otomatis gambar, kemudian gambar akan dikonversi ke dalam ruang warna HSV, kemudian user dapat memilih untung klasifikasi citra buah tersebut menggunakan metode K-NN atau SVM seperti yang ditampilkan pada gambar.

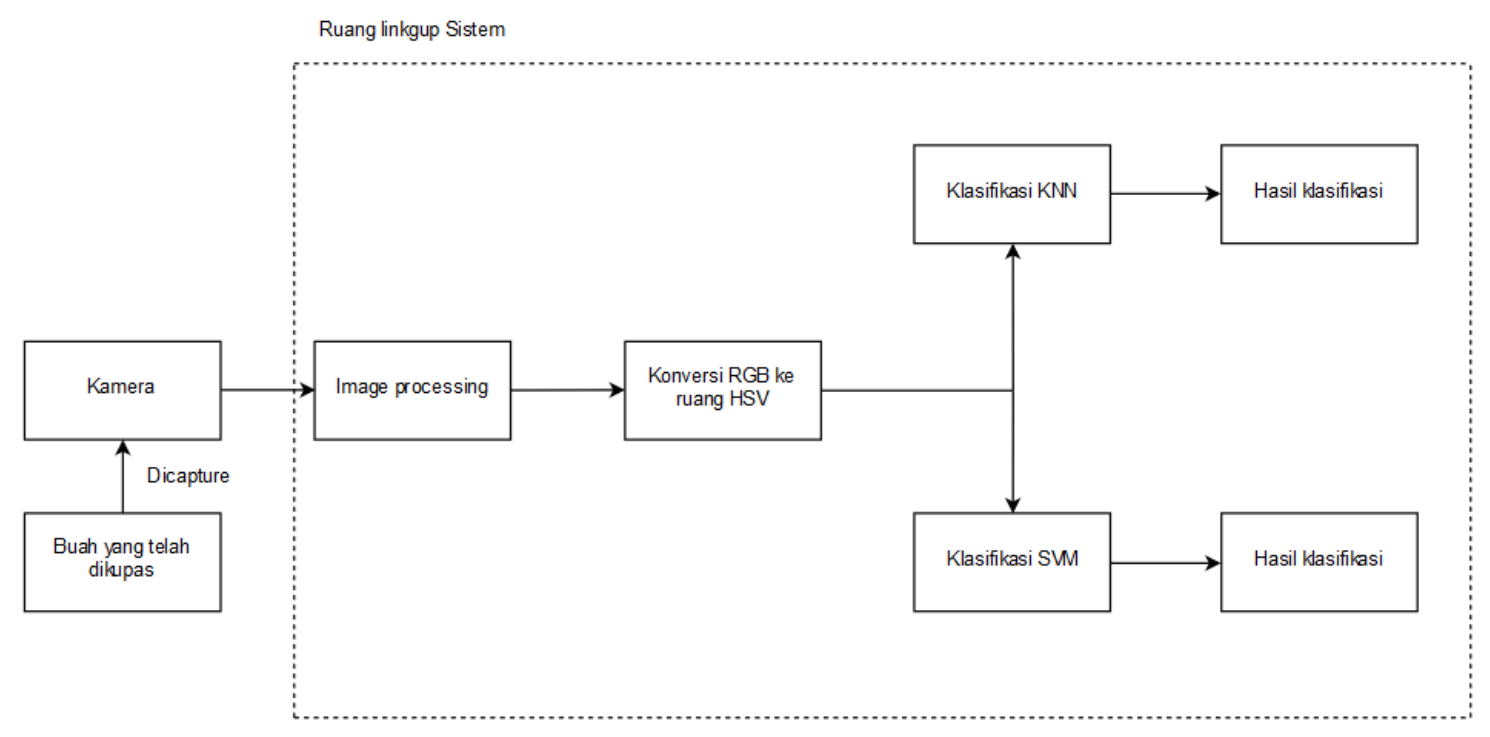

\section{Gambar 1. Cara Kerja Sistem}

Berdasarkan Gambar 1 dapat dilihat sistem yang dibangun dimulai dari image processing hingga mendapatkan output, sedangkan proses capture citra buah mangga menggunakan kamera merupakan di luar cakupan sistem. Adapun cara kerja klasifikasi proses SVM dan KNN sebagai berikut : 


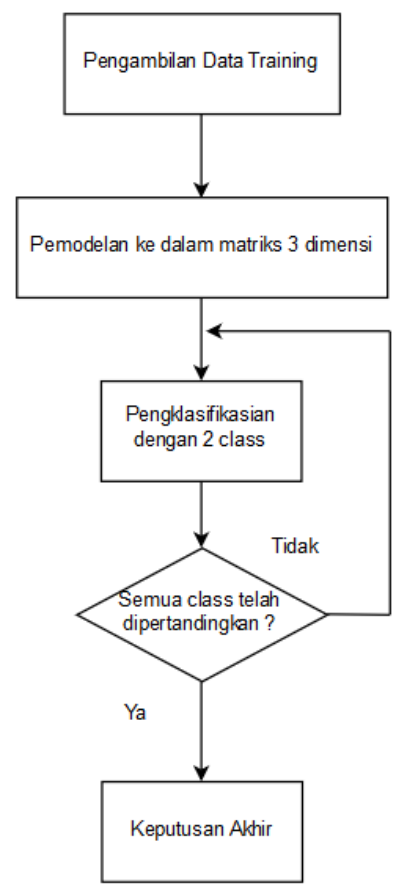

\section{Gambar 2. Cara Kerja SVM}

Berdasarkan Gambar 2 dapat dilihat cara kerja SVM meliputi langkah-langkah berikut :

1. Pengambilan data training

2. Pemodelan data training ke dalam matriks 3 dimensi

3. Melakukan pertandingan antar 2 kelas

4. Ulangi langkah ke-3 hingga sejumlah kelas telah selesai dipertandingkan

5. Mengambil keputusan akhir berdasarkan class yang paling banyak memenangkan pertandingan.

Setelah dilakukan pembangunan, kemudian dilakukan implementasi dan pengujian sistem dengan kata lain dilakukan pengukuran akurasi pada sistem pengenalan tingkat kemanisan mangga berdasarkan fitur warna. Pada pembuatan aplikasi NetBeans, digunakan metode pengembangan sistem prototype.

Berikut ini merupakan hasil sistem yang berhasil dibuat :

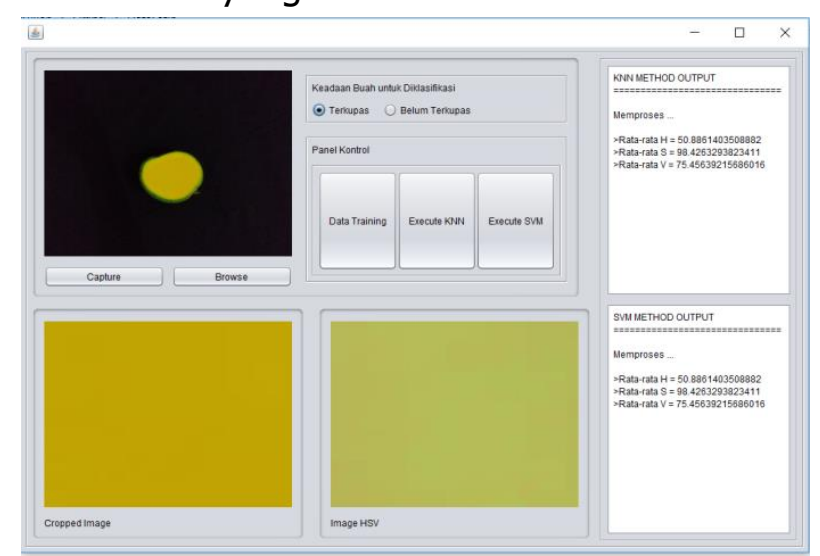

Gambar 3. Tampilan Sistem

MIND-20 
Hasil pengukuran akurasi dilakukan untuk mengetahui kinerja dari sistem pengenalan tingkat kemanisan mangga berdasarkan citra warna yang telah dibuat. Pengukuran tersebut dilihat dari beberapa aspek parameter diantaranya:

- Perbandingan akurasi klasifikasi menggunakan metode K-NN berdasarkan citra warna dengan output dari refractometer.

- Perbandingan akurasi klasifikasi menggunakan metode SVM berdasarkan citra warna dengan output dari refractometer.

Untuk menghitung tingkat akurasi pengujian dapat menggunakan rumus yang ditunjukkan pada table 4. Adapun analisis perbandingan akurasi akan ditunjukkan pada Tabel 5.

$$
\text { Tingkat Akurasi }=\frac{\text { Data Berhasil }}{\text { Jumlah Data }} \times 100 \%
$$

Dimana :

Jumlah Data adalah banyaknya data masukkan yang diproses sistem

Data berhasil adalah kecocokan antara keluaran sistem dengan output dari alat refractometer.

\section{Tabel 5. Pengukuran Akurasi Sistem}

\begin{tabular}{llll}
\multicolumn{3}{l}{$\begin{array}{l}\text { Hasil perbandungan akurasi pengukuran } \\
\text { output hasil }\end{array}$ Refractometer } & \multicolumn{3}{l}{ kingat kemanisan SVM dan KNN dengan } \\
No Uji & Hasil refractometer & KNN & SVM \\
1 & Manis & Manis & Manis \\
2 & Manis & Manis & Manis \\
3 & Manis & Manis & Manis \\
4 & Manis & Manis & Manis \\
5 & Manis & Manis & Manis \\
6 & Manis & Manis & Manis \\
7 & Manis & Manis & Manis \\
8 & Manis & Belum Manis & Manis \\
9 & Manis & Belum Manis & Manis \\
10 & Sedang & Sedang & Sedang \\
11 & Sedang & Belum Manis & Sedang \\
12 & Sedang & Sedang & Sedang \\
13 & Sedang & Sedang & Sedang \\
14 & Belum Manis & Sedang & Belum Manis \\
15 & Belum Manis & Sedang & Belum Manis \\
16 & Sedang & Sedang & Sedang \\
17 & Sedang & Sedang & Sedang \\
18 & Manis & Manis & Manis \\
19 & Manis & Manis & Manis \\
20 & Manis & Manis & Manis \\
21 & Manis & Manis & Manis \\
22 & Manis & Manis & Manis \\
23 & Sedang & Sedang & Belum Manis \\
24 & Sedang & Sedang & Sedang \\
& & &
\end{tabular}

Berdasarkan pengujian yang telah dilakukan sebelumnya, maka didapatkan tingkat akurasi sistem secara keseluruhan dalam melakukan proses klasifikasi tingkat kemanisan mangga berdasarkan citra warna dengan hasil prosentasi sebagai berikut: 


$\begin{array}{ll}\text { KNN } & \text { SVM } \\ \text { Tingkat Akurasi } & \text { Tingkat Akurasi } \\ =\frac{20}{24} \times 100 \% & =\frac{21}{24} \times 100 \% \\ =83.3 \% & =87.5 \%\end{array}$

\section{KESIMPULAN}

Dari pengujian sistem dapat diambil kesimpulan bahwa tingkat akurasi atau kesesuaian sistem pengenalan tingkat kemanisan mangga berdasarkan citra warna buah untuk menggunakan metode KNN memiliki prosentasi akurasi sebesar $83.3 \%$, sistem mampu mengklasifikasikan citra buah mangga dengan benar berjumlah 20 buah dari 24 buah yang diuji dengan pengaturan parameter $\mathrm{k}=7$, sedangkan akurasi atau sistem pengenalan tingkat kemanisan mangga berdasarkan citra warna buah menggunakan metode SVM memiliki prosentasi sebesar $87.5 \%$, sistem mapu mengklasifikasikan citra buah mangga dengan benar berjumlah 21 buah dari 24 buah yang diuji.

Sehingga dapat disimpulkan bahwa metode SVM memiliki akurasi lebih tinggi dibandingkan KNN pada penelitian ini adapun kelebihan dan kelemahan masing-masing metode adalah.

Kelebihan metode SVM berdasarkan penelitian ini adalah mampu menghasilkan model klasifikasi yang baik meskipun dilatih dengan himpunan data yang relatif sedikit. Kelemahan metode SVM berdasarkan penelitian ini adalah sulit diaplikasikan untuk himpunan dengan jumlah dimensi yang sangat besar. Kelebihan metode K-NN berdasarkan penelitian ini adalah Mudah diimplementasikan hanya dengan mengatur satu parameter k, dengan kelemahan adalah sulit mengklasifikasikan pola-pola yang tersebar acak.

\section{DAFTAR PUSTAKA}

Anonim, 2016, Metode Waterfall Definisi dan Tahapan (online),

(http://www.pengetahuandanteknologi.com/2016/09/metode-waterfall-definisi-

tahapan.html, diakses 6 April 2018)

Anonim, 2018, Metode K-NN (online), (https://id.wikipedia.org/wiki/KNN, diakses 6 April 2018).

Anonim, 2018, Buah Mangga (online), (https://id.wikipedia.org/wiki/Mangga, diakses 6 April 2018).

Anonim, 2018, Mangga Cengkir (online),

(https://id.wikipedia.org/wiki/Berkas:Mangga indramayu 071007-0327 rwg.jpg, diakses 6

April 2018). 
Agustina., dkk., 2015., Penentuan Mutu Mangga Arumanis (Mangifera Indica L.) Secara Nondestruktif Menggunakan NIR Spectroscopy.

Indarto., 2017., Deteksi Kematangan Buah Pisang Berdasarkan Fitur Warna Citra Kulit Pisang Menggunakan Metode Transformasi Ruang Warna HIS.

Kusumaningtyas., Rosa Andrie Asmara., 2016., Identifikasi Kematangan Buah Tomat Berdasarkan Warna Menggunakan Metode Jaringan Syaraf Tiruan (JST).

Muhammad., dkk., 2017., Pengenalan Wajah Menggunakan SVM Multi Kernel dengan Pembelajaran yang Bertambah.

Qur'ania., dkk., 2016. Analisis Tekstur dan Ektraksi Fitur Warna Untuk Klasifikasi Apel Berbasis Citra.

Rianto., Agus Harjoko., 2017., Penentuan Kematangan Buah Salak Pondoh Di Pohon Berbasis Pengolahan Citra Digital.

Sembiring., 2007., Penerapan Teknik Support Vector Machine untuk Pendeteksian Intrusi pada Jaringan.

Susilowati., dkk 2015., Implementasi Metode Support Vector Machine Untuk Melakukan Klasifikasi Kemacetan Lalu Lintas Pada Twitter.

WANHAR., DKK., 2016, KLASIFIKASI MUTU BUAH MANGGA DENGAN MENGGUNAKAN JARINGAN SYARAF TIRUAN.

Yulia., Puji Subekti., 2016., Klasifikasi Level Kematangan Buah Tomat Berdasarkan Fitur Warna Menggunakan SVM.

YULIANA., 2016, IDENTIFIKASI RASA BUAH MANGGA GEDONG GINCU CIREBON BERDASARKAN CITRA RED-GREEN-BLUE MENGGUNAKAN JARINGAN SYARAF TIRUAN.

Bionutrient, 2016, Fruit Index, (Online) http://bionutrient.org/sites/all/files/doc/fruits/RefractiveIndexOfJuices.pdf) 